\title{
Work Group Diversity and Group Performance: An Integrative Model and Research Agenda
}

\author{
Daan van Knippenberg \\ Erasmus University Rotterdam
}

\author{
Carsten K. W. De Dreu and Astrid C. Homan \\ University of Amsterdam
}

\begin{abstract}
Research on the relationship between work group diversity and performance has yielded inconsistent results. To address this problem, the authors propose the categorization-elaboration model (CEM), which reconceptualizes and integrates information/decision making and social categorization perspectives on work-group diversity and performance. The CEM incorporates mediator and moderator variables that typically have been ignored in diversity research and incorporates the view that information/decision making and social categorization processes interact such that intergroup biases flowing from social categorization disrupt the elaboration (in-depth processing) of task-relevant information and perspectives. In addition, the authors propose that attempts to link the positive and negative effects of diversity to specific types of diversity should be abandoned in favor of the assumption that all dimensions of diversity may have positive as well as negative effects. The ways in which these propositions may set the agenda for future research in diversity are discussed.
\end{abstract}

Work-group diversity is a fact of organizational life. It is also a key concern for theory and practice in organizational behavior. Groups in organizations have become more diverse in terms of their demographic composition over the years and will continue to become more diverse in years to come (Jackson, 1992; Triandis, Kurowski, \& Gelfand, 1994; Williams \& O'Reilly, 1998). In addition, organizations are increasingly turning to the use of crossfunctional teams, thus increasingly introducing functional diversity in work groups. Because work-group diversity may have positive as well as negative effects on group performance (e.g., Guzzo \& Dickson, 1996; Milliken \& Martins, 1996; Williams \& O'Reilly, 1998), the questions of which processes underlie these effects of diversity and how to manage these processes pose major challenges to organizational theory and practice.

Unfortunately, research on the positive and negative effects of work-group diversity has largely developed in separate research traditions, and an integrative theoretical framework from which to understand the effects of diversity on group performance is missing (Guzzo \& Dickson, 1996; Kozlowski \& Bell, 2003; Williams \& O'Reilly, 1998). Indeed, even though contemporary models of diversity seem able to explain the positive or negative effects of diversity when they occur, they are less able to predict when each occurs. As a case in point, recent attempts at meta-analytical

Daan van Knippenberg, Rotterdam School of Management, Erasmus University Rotterdam, Rotterdam, the Netherlands; Carsten K. W. De Dreu and Astrid C. Homan, Department of Psychology, University of Amsterdam, Amsterdam, the Netherlands.

We are indebted to Barbara van Knippenberg, Bernard Nijstad, Frederic Damen, Laurens Rook, and Wendy van Ginkel for their valuable comments on drafts of this article.

Correspondence concerning this article should be addressed to Daan van Knippenberg, Rotterdam School of Management, Erasmus University Rotterdam, P.O. Box 1738, 3000 DR, Rotterdam, the Netherlands. E-mail: dvanknippenberg@fbk.eur.nl integration have not been very successful in linking diversity with performance (Bowers, Pharmer, \& Salas, 2000; Webber \& Donahue, 2001; also see Wood, 1987). To meet this challenge and to advance our understanding of the effects of work-group diversity on group performance, we introduce a model of the processes underlying the positive and the negative effects of diversity that we believe has greater predictive power and opens up new directions in research on diversity and group performance. We begin with a brief review of the state of the art in diversity research to position our model and the problem it aims to address. We then introduce our model and discuss its core propositions, highlighting their implications for diversity research.

\section{State of the Art: A Brief Review of Work-Group Diversity and Performance}

Diversity refers to differences between individuals on any attribute that may lead to the perception that another person is different from self (e.g., Jackson, 1992; Triandis et al., 1994; Williams \& O'Reilly, 1998). In principle, diversity thus refers to an almost infinite number of dimensions, ranging from age to nationality, from religious background to functional background, from task skills to relational skills, and from political preference to sexual preference. In practice, however, diversity research has mainly focused on gender, age, race/ethnicity, tenure, educational background, and functional background (Milliken \& Martins, 1996; Williams \& O’Reilly, 1998). A number of researchers have proposed that the most important difference underlying diversity dimensions is that between social category diversity- differences in readily detectable attributes such as sex, age, and ethnicity - and informational/functional diversity - differences in less visible underlying attributes that are more job-related, such as functional and educational background (Jackson, 1992; Jehn, Northcraft, \& Neale, 1999; Milliken \& Martins, 1996; Tsui, Egan, \& O’Reilly, 1992). 
In a comprehensive review of the literature, Williams and O'Reilly (1998) identified two main traditions in research in work-group diversity and performance: the social categorization perspective and the information/decision-making perspective. The social categorization perspective holds that similarities and differences are used as a basis for categorizing self and others into groups, with ensuing categorizations distinguishing between one's own in-group and one or more out-groups. People tend to like and trust in-group members more than out-group members and thus generally tend to favor in-groups over out-groups (Brewer, 1979; Tajfel \& Turner, 1986; Turner, Hogg, Oakes, Reicher, \& Wetherell, 1987). Consistent with research on similarity/attraction (Williams \& O'Reilly, 1998), this signifies that work group members are more positively inclined toward their group and the people within it if fellow group members are similar rather than dissimilar to the self. Moreover, categorization processes may produce subgroups within the work group (i.e., "us" and "them"), and give rise to problematic inter-subgroup relations. As a result, the more homogeneous the work group, the higher member commitment (Riordan \& Shore, 1997; Tsui et al., 1992) and group cohesion (O'Reilly, Caldwell, \& Barnett, 1989) will be, the fewer relational conflicts will occur (Jehn et al., 1999; Pelled, Eisenhardt, \& Xin, 1999), and the less likely membership will be to turn over (Wagner, Pfeffer, \& O'Reilly, 1984). Together, these processes are proposed to result in higher overall group performance when groups are homogeneous rather than heterogeneous (for evidence, see Jehn et al., 1999; Murnighan \& Conlon, 1991; Simons, Pelled, \& Smith, 1999).

The information/decision-making perspective arrives at quite different predictions, holding that diverse groups should outperform homogeneous groups. The idea is that diverse groups are more likely to possess a broader range of task-relevant knowledge, skills, and abilities that are distinct and nonredundant and to have different opinions and perspectives on the task at hand. This not only gives diverse groups a larger pool of resources, but may also have other beneficial effects. The need to reconcile conflicting viewpoints may force the group to more thoroughly process taskrelevant information and may prevent the group from opting too easily for a course of action on which there seems to be consensus. In addition, exposure to diverging and potentially surprising perspectives may lead to more creative and innovative ideas and solutions (Ancona \& Caldwell, 1992; Bantel \& Jackson, 1989; De Dreu \& West, 2001). Corroborating this analysis, some studies found an association of diversity with increased task conflict (Jehn et al., 1999; Pelled et al., 1999) and higher performance and innovation (Bantel \& Jackson, 1989; Cox, Lobel, \& McLeod, 1991; Jehn et al., 1999).

Whereas the social categorization perspective focuses more on relational aspects, the information/decision-making perspective concentrates on task-related aspects of group processes. One could thus argue that diversity negatively affects relationships within the group while simultaneously contributing to group performance (Triandis et al., 1994). However, because problematic intragroup relations and low group cohesiveness are detrimental to performance (De Dreu \& Weingart, 2003b; Jehn, 1995; Mullen \& Copper, 1994), it is difficult to see how diversity could negatively affect relationships while at the same time stimulate performance.

An alternative way to integrate social categorization and information/decision-making perspectives is to take the dimensions of diversity into account. Social categorization theories out- line how categorizations are more likely to be used if category markers are readily detectable, such as in the case of differences in sex and race (Fiske, 1998). Moreover, categorizations that are more cognitively accessible are more likely to be used. This renders categorizations that people have been socialized into using throughout their life (i.e., such as sex, age, and race/ethnicity) particularly likely to be used (A. van Knippenberg \& Dijksterhuis, 2000). Accordingly, one may argue that the social categorization effects of diversity should be more likely to occur for such readily observable characteristics as sex and ethnicity (i.e., social category diversity) than for more "hidden" dimensions of diversity such as functional or educational background. The positive effects of diversity, in contrast, are linked to differences in information, expertise, viewpoints, and so forth. Thus, one may argue that diversity only has positive effects on group performance to the extent that it covaries with informational differences. Indeed, it has been proposed that although demographic differences in, for instance, sex, age, and ethnicity may be associated with such informational differences (Cox et al., 1991; Tsui \& O’Reilly, 1989), more job-related dimensions such as functional and educational background (i.e., informational diversity) are more likely to be associated with (job-relevant) informational differences (Pelled et al., 1999). The positive effects of diversity, as outlined in the information/decision-making perspective, therefore, would be more likely to occur for diversity on underlying job-related attributes.

Although the logic behind this reasoning seems sound, there is insufficient empirical support for the proposition that the effects of diversity are contingent on diversity type (i.e., social category vs. informational diversity). Some studies have yielded evidence consistent with this proposition (e.g., Jehn et al., 1999), whereas others revealed positive performance effects of demographic differences (e.g., Cox et al., 1991) or negative performance effects of differences in job-related attributes (e.g., Simons et al., 1999). Moreover, recent meta-analyses by Bowers et al. (2000) and Webber and Donahue (2001) failed to support the proposition that diversity type moderates the effects of diversity on performance. These studies showed that neither diversity on readily observable attributes nor diversity on underlying job-related attributes could be reliably linked to group performance.

\section{The Categorization-Elaboration Model}

Previous research and theory thus has not been able to adequately account for the positive and negative effects diversity in work groups can have or to integrate the social categorization and information/decision-making perspective in a satisfactory way. To address this problem, we propose the categorization-elaboration model (CEM). The CEM identifies a number of reasons why diversity research has yielded such inconsistent findings, each of which is discussed in more detail in the following sections. First, diversity research has paid insufficient attention to group information processing, and to important moderators of group information processing, as the process underlying the positive effects of diversity. Second, diversity research has often worked from a somewhat oversimplified conceptualization of social categorization processes. This has apparently led diversity research to largely ignore important moderators of the relationships between diversity and social categorization and between social categorization and the negative consequences of categorization (i.e., intergroup bias). 
Third, diversity research has typically studied information/ decision-making processes and social categorization processes in isolation, whereas the CEM suggests that information/decision making and social categorization processes interact. Finally, much diversity research has worked from the assumption that information/decision-making and social categorization processes are each associated with particular dimensions of diversity. Our reconsideration of the nature of these processes suggests, however, that each dimension of diversity may in principle elicit both information/decision-making and social categorization processes. This reconceptualization and integration of information/decisionmaking and social categorization perspectives in the CEM points to mediator and moderator variables that typically have been ignored in diversity research and suggests a research agenda for future research in diversity and group performance that may resolve many of the inconsistent findings in diversity research.

The CEM is depicted in Figure 1. Building on the information/ decision-making perspective, we propose that diversity within a group is positively related to the elaboration of task-relevant information and perspectives within the group - that is, to group members' exchange, discussion, and integration of ideas, knowledge, and insights relevant to the group's task. Elaboration of task-relevant information and perspectives, in turn, is proposed to be related to group performance, especially to group creativity, innovation, and decision quality. This is not to say, however, that diversity within a group will always lead to elaboration of taskrelevant information and perspectives. Accordingly, we identify factors that moderate the relationship between diversity and elaboration. In brief, we propose that diversity in a group is most likely to lead to elaboration of task-relevant information and perspectives when the group task has strong information-processing and decision-making components, when the group is highly motivated to process task-relevant information and perspectives, and when group members are high in task ability.

Consistent with the social categorization perspective in diversity research, we also attribute a role to social categorization (the differentiation between in-group others, who are subjectively similar to self, and outgroup others, who are subjectively dissimilar to self). Building on theory and research in social categorization, we propose that the extent to which differences between group members engender social categorization is contingent on three factors: the cognitive accessibility, the normative fit, and the comparative fit of the categorization. Cognitive accessibility refers to the ease with which the social categorization implied by the differences (e.g., men vs. women) is cognitively activated. Normative fit reflects the extent to which the categorization makes subjective sense to group members. Comparative fit refers to the extent to which the categorization yields subgroups with high intragroup similarity and high intergroup differences. We also note that social categorization per se should not be equated with intergroup biases (more favorable responses to others categorized as in-group than others categorized as out-group) that may flow from social categorization and argue that intergroup bias and not social categorization per se is disruptive to diverse groups. A key question thus

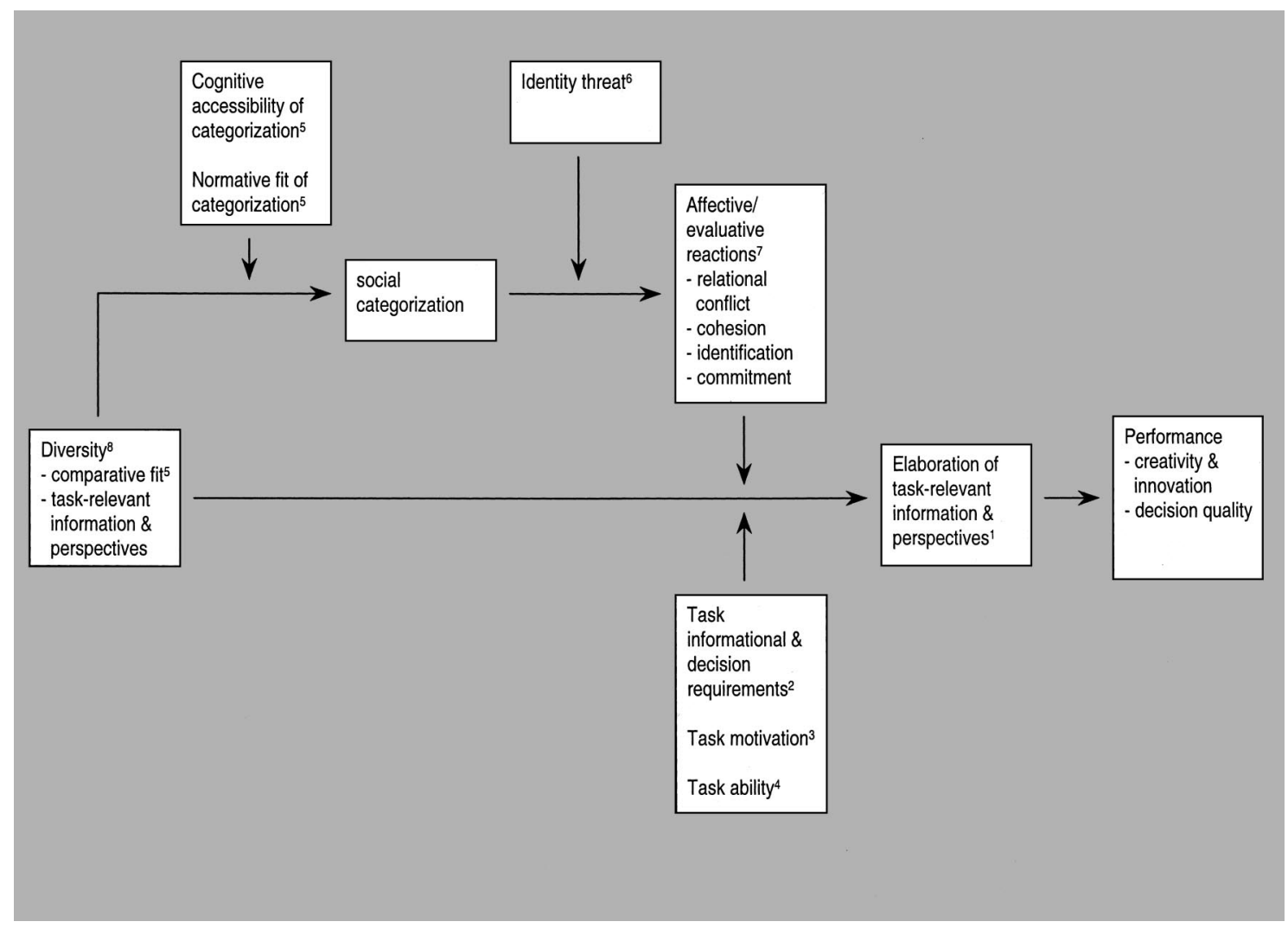

Figure 1. The categorization-elaboration model of work group diversity and group performance. Superscripts refer to the correspondingly numbered propositions discussed in the text. 
is under what conditions social categorization results in intergroup bias. We propose that threats and challenges to subgroup identity are the main factors driving intergroup bias.

Integrating the information/decision-making and social categorization perspectives that have developed as separate traditions, we propose that elaboration and social categorization processes interact in that the intergroup biases that may result from social categorization disrupt elaboration of task-relevant information and perspectives. Finally, in contrast to earlier attempts to link the positive and negative effects of diversity to specific types of diversity, we propose that all dimensions of diversity may elicit elaboration of task-relevant information as well as social categorization processes.

Each of these propositions is discussed in the following sections. This discussion highlights how these propositions help resolve inconsistencies among findings in diversity research and may assist in setting the agenda for future research. First, we discuss our propositions regarding diversity and the elaboration of taskrelevant information. Next, we take a closer look at the relationship between diversity, social categorization, and intergroup bias. Integrating these first two sections, we follow with a discussion of the ways in which intergroup biases may disrupt the elaboration of task-relevant information and perspectives in diverse groups. Finally, we outline the ways in which all dimensions of diversity may engender elaboration as well as social categorization processes. To further clarify our propositions and highlight the research implications, we conclude each section with a discussion of implications for research. We end with the applications our model might have for diversity management.

\section{Diversity and the Elaboration of Task-Relevant Information}

Part of the potential advantage of diverse groups over homogeneous groups lies in the greater pool of task-relevant information and expertise diverse groups may have at their disposal. In addition, the larger social network of diverse groups may give diverse groups more access to new information and a potentially larger basis of support for decisions than homogeneous groups (Ancona $\&$ Caldwell, 1992). Our concern here, however, is with the group processes engendered by diversity. Arguably, these processes are the key to realizing diversity's potential, because it is not the availability of information per se but the use of this information in group task performance that lies at the basis of diverse groups' potentially superior performance. With regard to these processes, however, we identify two problems in the diversity literature. First, the processes underlying the positive effects of diversity are typically conceptualized and operationalized in terms of conflict and dissent, but the available evidence does not support a positive relationship between conflict and performance (De Dreu \& Weingart, 2003b). Second, and closely related to the first concern, the nature of the performance that is expected to benefit from diversity is ill-defined.

The information/decision-making processes that are proposed to underlie the positive effects of diversity are typically operationalized as conflict or dissent (e.g., Jehn et al., 1999; Pelled et al., 1999). Differences in information and viewpoints may give rise to task conflict and dissent; faced with the need to solve these conflicts and reconcile opposing views, group members may engage in more elaborate processing of task-relevant information and search for more creative problem solutions than would be the case in the absence of conflict and dissent. As a result, task conflict and dissent may be associated with better and more creative group performance (e.g., De Dreu, Harinck, \& van Vianen, 1999; Tjosvold, 1998). Although this analysis holds intuitive appeal, a number of considerations suggest that conflict and dissent are at best only a proxy of, or a precursor to, the processes that underlie the positive effect of diversity on group performance.

First, a meta-analysis of the conflict literature shows that task conflict is negatively related to group performance (De Dreu \& Weingart, 2003b). Second, it is not so much the presence or absence of conflict but instead the way conflicts are managed that helps or hinders teams to perform effectively (De Dreu \& Weingart, 2003a; Lovelace, Shapiro, \& Weingart, 2001; Simons \& Peterson, 2000; Tjosvold, 1998). For instance, when group members decide to avoid rather than confront conflict of opinions, the potentially beneficial effects of diversity will not be harvested. Third, and perhaps most important, performance does not benefit from conflict and dissent per se but from the process that conflict and dissent is assumed to promote: the deep-level and creative processing of diverse information and viewpoints. However, the exchange of diverse information, ideas, and viewpoints may also stimulate such in-depth processing without conflict or dissent (i.e., one may process new information without initially disagreeing with the position implied by the information). It is possible that under certain conditions conflict and dissent may promote this process, but as suggested above, it may also disrupt this process (e.g., when groups opt for a quick compromise to avoid the conflict). The bottom line therefore is that conflict and dissent are not necessary to realize the potential benefits of diversity nor are they always conducive to realizing these benefits.

Accordingly, we propose that elaboration of task-relevant information is the primary process underlying the positive effects of diversity on performance. Building on the conceptualization of groups as information processors (Hinsz, Tindale, \& Vollrath, 1997), elaboration is defined as the exchange of information and perspectives, individual-level processing of the information and perspectives, the process of feeding back the results of this individual-level processing into the group, and discussion and integration of its implications. It is this elaboration, then, that may be engendered by work-group diversity, and that may lead diverse groups to outperform more homogeneous groups. Consider, for example, an information technology company that relies on crossfunctional project teams consisting of designers, programmers, and sales and after-sales representatives to develop and sell tailor-made software packages. High-quality performance requires that team members inform the team on the basis of their own expertise about the different issues involved (e.g., customer wishes, design and program possibilities, costs), carefully process the perspectives introduced by other team members to understand the implications for their own area of expertise, feed these implications back to the team, and through integration of perspectives design the optimal product.

First evidence for the role of elaboration in diverse groups comes from a recent experimental study of decision making in informationally diverse groups by van Ginkel and van Knippenberg (2003). In this study, the extent to which group members had a shared representation of the task (i.e., a shared mental model; Cannon-Bowers \& Salas, 2001) that stressed the sharing and processing of diverse information and viewpoints (i.e., elaboration 
of task-relevant information) was manipulated through task instructions and group discussion of these instructions. Results showed that groups with shared mental models emphasizing elaboration made higher quality decisions than groups that held such shared task representations to a lesser extent.

Proposition 1: The primary process underlying the positive effects of diversity on group performance is elaboration of task-relevant information.

\section{Moderators of the Relationship Between Diversity and Elaboration}

A focus on elaboration of task-relevant information as the primary process driving the positive effects of diversity points to a number of important moderator variables that probably flow less obviously from an emphasis on conflict and dissent or from other, more loosely defined approaches to information/decision-making processes. As discussed in the previous section, the proposition that diverse groups may outperform more homogeneous groups follows from the reasoning that the exposure to more diverse information and perspectives may promote elaboration of taskrelevant information. This, in turn, would be expected to lead to more thorough and creative information processing, problem solving, and decision making. Such expected outcomes, then, give rise to the proposition that diversity may benefit performance to the extent that performance requires information processing, creative and innovative idea generation and problem solving, and/or highquality decision making. That is, group performance should benefit primarily from diversity on complex and nonroutine information-processing and decision-making tasks where performance is primarily defined in terms of the quality of the group's product, such as those facing research and development teams. Indeed, such tasks may be expected to invite more elaborate information processing in the first place (Stewart \& Barrick, 2000; Van de Ven, Delbecq, \& Koenig, 1976), setting the stage for the potentially positive effects of diversity of information and perspectives. In contrast, there appears little reason to expect that simple and routine tasks (e.g., repetitive production tasks) typically invite extensive information processing. In fact, elaboration of task information in routine tasks may result in abandoning otherwise reasonable work procedures and thus may be counterproductive (De Dreu \& Weingart, 2003b; Schwenk, 1990). Task informationprocessing and decision-making requirements, therefore, should be a key moderator of the effects of work-group diversity on performance.

Although diversity research typically has not focused on task requirements, there is some evidence in support of this proposition. Jehn et al. (1999) found that informational diversity was positively related to performance when task complexity was high rather than low. The meta-analysis by Bowers et al. (2000) similarly suggests that diverse groups may outperform homogeneous groups on difficult tasks, whereas homogeneous groups might in fact outperform diverse groups on more simple tasks.

Proposition 2: Task requirements moderate the relationship between diversity and performance such that diversity may be positively related to performance when performance requires information processing and creative, innovative solutions.
The CEM's emphasis on elaboration also points to task motivation and ability as core moderators of the positive effects of diversity. Motivation and ability are more or less neglected variables in diversity research, but they are seen as the primary moderators of deep-level processing of information in social psychological models of social perception and judgment (Chaiken \& Trope, 1999). The proposition that deep-level processing of information is contingent on both the motivation and the ability to conduct such processing is supported in research in a variety of domains, including persuasive communication (Eagly \& Chaiken, 1993), person perception (Fiske, 1998), negotiation (De Dreu \& Carnevale, 2003), and group decision making (Kruglanski \& Webster, 1991). Accordingly, we propose that motivation and ability moderate the relationship between diversity and performance.

In the area of diversity, there is some support for this proposed role of motivation in a recent experiment by Scholten, van Knippenberg, Nijstad, and De Dreu (2003). Scholten et al. focused on the role of accountability in informationally diverse groups. Accountability to others for the way in which decisions are made has been shown to motivate more elaborate processing of information (Lerner \& Tetlock, 1999). The proposed role of motivation therefore suggests that accountability, as a factor affecting motivation, should influence performance in diverse groups. Scholten et al. examined the effects of accountability on group decision quality in a decision task in which the best decision alternative could be identified through the exchange and processing of information uniquely assigned to individual group members (see Stasser, 1999). As predicted, and consistent with the proposed role of motivation, Scholten et al. found that accountable groups engaged in deeper information processing and reached better quality decisions.

Proposition 3: Diversity is more likely to engender elaboration and to benefit performance when group member task motivation is high rather than low.

Proposition 4: Diversity is more likely to engender elaboration and to benefit performance when group member task ability is high rather than low.

\section{Research Implications of Propositions 1 Through 4}

Propositions 1 through 4 point to a number of factors that have received little if any attention in diversity research. Proposition 1 points to a first reason why diversity research yields inconsistent findings. Elaboration is likely to be more unambiguously related to task performance than conflict and dissent, and a focus on elaboration and the conditions under which diversity engenders elaboration (i.e., Propositions 2-4) is therefore likely to yield more consistent relationships with performance. An obvious implication for diversity research would therefore be to assess elaboration processes and to focus on the contingencies of elaboration.

Because the focus is on group-level elaboration (Hinsz et al., 1997), elaboration may in part be inferred from behavioral data that may for instance be obtained through audio-video recording of task groups. Such data can be coded for the exchange of information and perspectives (Stasser, 1999) and for discussion building on these exchanges. In addition, elaboration might be inferred from questionnaire data assessing self-reported elaboration, including the individual-level processing that may not be 
inferred from behavioral observations and aggregating these data to the group level (Homan \& van Knippenberg, 2003). Alternatively, research may be conducted along the lines of the study by van Ginkel and van Knippenberg (2003) discussed above and experimentally manipulate the extent to which groups engage in elaboration of task-relevant information and perspectives.

Although there already is some evidence for the moderating role of task requirements (Bowers et al., 2000; Jehn et al., 1999), future research should provide more direct evidence for Proposition 2 regarding the role of task information processing, creativity, and decision-making requirements. This may be done by including measures of elaboration of task-relevant information and perspectives in diversity research and relating these to either measures of task characteristics (cf. McGrath, 1984; Stewart \& Barrick, 2000) or to experimental manipulations of task requirements.

Proposition 3 suggests that an important avenue for future diversity research is to focus on motivation. One possibility is to assess group members' intrinsic motivation, to aggregate this to the work-group level, and to test interactions with dimensions of diversity. Because a host of factors may feed into motivation, Proposition 3 also points to a range of factors that may moderate the effects of diversity on performance through their effects on motivation. Examples include leadership (e.g., D. van Knippenberg \& Hogg, 2003), goal-setting (e.g., Locke \& Latham, 1990), organizational justice (e.g., Tyler, 1999), social exchange processes (e.g., Rhoades \& Eisenberger, 2002), individual differences in information-processing motivation (e.g., De Dreu \& Carnevale, 2003; Kruglanski \& Webster, 1996), accountability (e.g., Lerner \& Tetlock, 1999), and group members' motivation to work with the group (e.g., Weaver, Bowers, Salas, \& Cannon-Bowers, 1997). Because these factors typically have not been studied in relation to diversity, an important contribution of Proposition 3 is to bridge diversity research and the broad range of theories focusing on task motivation.

To directly test Proposition 4 about the moderating role of ability one may assess, for instance, intelligence or level of education (Hunter \& Schmidt, 1996), aggregate this to the group level, and test interactions between these proxies to ability and diversity. In addition to general cognitive ability, task-specific knowledge, skills, and abilities may be important, because they provide the common ground and shared frame of reference that may aid diverse groups in making sense of divergent information and perspectives. Communication skills too may be an important aspect of a work group's ability to process diverse information, because part of the group-level elaboration process is the effective communication of new information and perspectives (cf. the distinction between task skills and team skills; Kozlowski \& Bell, 2003). Accordingly, a test of hypotheses derived from Proposition 4 might focus on task-specific knowledge, skills, and abilities; communication skills; and more general measures of ability.

In a similar vein as Proposition 3, Proposition 4 points to a range of factors that may influence ability as moderators of the relationship between diversity and performance. The ability to elaborate task-relevant information may be something that group members bring to the group, but it may also be affected by situational factors. Elaborate processing of task-relevant information and perspectives requires time (cf. Schweiger, Sandberg, \& Rechner, 1989). Time constraints (e.g., deadlines) may thus put serious limits on a group's ability to elaborate. An experimental study by Kruglanski and Webster (1991) provides some evidence in support of this hypothesis. They observed that groups that worked on a decision task under time pressure were less open to divergent perspectives than groups that worked without such time constraints. Constraints on ability may also come from the working environment. Environmental "noise" may interfere with a group's ability to exchange and process diverse information. Kruglanski and Webster's (1991) second experiment provides evidence for this: Groups working in a noisy room were less open to divergent perspectives than groups not exposed to noise.

In relation to ability, we may also note that even highly skilled and accomplished group members may reach a point where their ability is not up to par with group diversity. For a given level of ability, we may assume that a group is able to benefit from diversity up to a certain degree of diversity but that diversity beyond this level will have no further benefit and may even disrupt group process with increasing diversity by introducing misunderstandings and so forth. Thus, even though more capable groups may be better equipped to harvest the benefits of diversity, the relationship of diversity with elaboration and performance is likely to be curvilinear rather than linear, with diversity stimulating elaboration and enhancing performance (contingent on ability) up to a point, beyond which more diversity no longer benefits performance and might even be detrimental to performance (i.e., an inverted U-shape). In contrast to earlier work (cf. Williams \& O'Reilly, 1998), the CEM thus suggests that diversity can have both positive and negative effects on performance through information/decision-making processes. Although more research is certainly needed, some early evidence for this derives from a study by Gonzalez-Roma, West, and Borrill (2003), who found curvilinear relationships with team innovativeness for team diversity in gender, age, and tenure. Brodbeck (2003), who distinguished between business game teams with low, moderate, and high diversity, likewise found that moderately diverse teams outperformed teams with lower and higher diversity.

\section{Diversity, Social Categorization, and Intergroup Bias}

The information/decision-making perspective and the social categorization perspective have largely developed along separate lines. Accordingly, little theoretical or empirical work in diversity research concerns the question of how social categorization processes may affect information/decision-making processes and, more specifically, elaboration processes. This is a question of considerable importance, because, as we argue in the next section, there is reason to expect that social categorization processes may disrupt elaboration of task-relevant information. Before we address this issue, however, we first consider the relationships among diversity, social categorization, and intergroup bias, because it is important to distinguish among the determinants of social categorization per se and the determinants of intergroup bias in research on diversity and performance.

Most empirical research from the social categorization perspective on diversity has been conducted under the implicit assumption that social categorization is merely a function of the degree of difference between group members. Moreover, such research has generally adopted an independent effects approach, assuming that diversity on a dimension (e.g., ethnicity) is predictive of social categorization independent from diversity on other dimensions (e.g., age; Pelled et al., 1999). An implicit assumption operating in such research is that social categorization more or less inevitably 
results in intergroup biases, that is, less positive reactions to others categorized as dissimilar, or of out-group status, than to others categorized as similar, or of in-group status (cf. Williams \& O'Reilly, 1998). Accordingly, most field studies of diversity use a measure of diversity that reflects the degree of similarity among group members on a given dimension and relate this to outcomes without assessing mediating processes (e.g., Riordan \& Shore, 1997; Tsui et al., 1992). In a similar vein, experimental studies typically do not go beyond manipulating group composition as being either diverse or homogeneous on a dimension of interest (e.g., Cox et al., 1991). Interactions between different dimensions of diversity typically are not tested, either in the field or in the lab (Pelled et al., 1999; Williams \& O'Reilly, 1998).

These common practices are unfortunate because research and theory on social categorization, social identity, and intergroup relations suggests more complex relationships between diversity and categorization and between categorization and intergroup bias (e.g., Brewer \& Brown, 1998; Brown \& Gaertner, 2001; D. van Knippenberg, 2003). Accordingly, applying insights acquired from diversity research should improve the explanatory power of models of work-group diversity.

\section{The Salience of Social Categorizations}

First, we address the relationship between diversity and social categorization. Diversity may lead group members to distinguish between "us" and "them." Many work groups offer several potential bases for such us-versus-them distinctions (e.g., men vs. women, old vs. young, sales vs. production), and not all of these potential categorizations are necessarily used by the individuals in the particular situation in question. A core question for diversity research, therefore, is which factors determine the likelihood that individuals view the self and others in terms of a particular categorization, that is, what renders it salient in people's minds? The answer to this question is important to our understanding of diversity effects, because it directly relates to the likelihood that differences between work-group members elicit social categorization processes. As a case in point, Randel (2002) assessed the salience of gender categorization in a questionnaire and found that salience moderated the relationship between gender composition and relational conflict such that the relationship was stronger when gender was more salient. Somewhat surprisingly, then, diversity research typically has not focused on the determinants of social category salience.

Self-categorization theory proposes that the salience of social categorizations is a function of three factors (Oakes, Haslam, \& Turner, 1994; Turner et al., 1987): comparative fit, normative fit, and cognitive accessibility. The comparative fit of a categorization refers to the extent to which the categorization provides a good reflection of similarities and differences between people. The more a categorization results in high within-category similarity and high between-category differences, the higher is its comparative fit and the more likely the categorization is to be salient. Consider, for example, transnational teams, in which members come from several different countries. Consistent with the principle of comparative fit, Earley and Mosakowski (2000) argued that within a team consisting of many different nationalities, categorization into same-nationality subgroups would not be easy, if at all possible, whereas within teams consisting of two nationalities, categorization in terms of nationality would be more salient (also see Lau \&
Murnighan, 1998). These authors indeed observed more subcategorization on perceptual-attitudinal measures within teams incorporating two nationalities than within teams incorporating several different nationalities or within those that are homogeneous. The effects of comparative fit have mainly been demonstrated in research on cross-categorization, which points to the fact that different dimensions of diversity may interact in determining the salience of social categorizations (Brewer, 1995; Lau \& Murnighan, 1998). When people differ on more than one dimension, differences may either converge (i.e., be correlated) or cross-cut each other (i.e., be unrelated). When differences converge (e.g., all the male members of a work group are relatively young while all the female members are relatively old), social categorization (i.e., younger men vs. older women) is more likely then when differences along the dimensions cross-cut each other (e.g., older and younger group members are equally likely to be either male or female; Homan \& van Knippenberg, 2003; Marcus-Newhall, Miller, Holtz, \& Brewer, 1993; Oakes, Turner, \& Haslam, 1991).

The second component underlying the salience of social categorization, namely, normative fit, reflects the extent to which the categorization makes sense in relation to the individual's cognitive frame of reference (e.g., beliefs, expectations, stereotypes). The more an individual believes that within the given context differences along a certain dimension are meaningful, the more salient the categorization based on these differences will be. Stangor, Lynch, Duan, and Glass (1992), for example, showed that individuals with racial prejudices (i.e., for whom race is more strongly associated with meaningful differences) are more likely to use race categorizations than are those who are less racially prejudiced. The subjective meaningfulness of categorization depends not only on individual differences but also on contextual differences. Some jobs, for instance, such as construction work or truck driving, seem to be more strongly associated with stereotypic beliefs about gender differences than others. In line with this view, D. van Knippenberg, Haslam, and Platow (2003) proposed that the extent to which group identification is affected by diversity on a particular dimension is contingent on beliefs about the extent to which that dimension is relevant to the task at hand (i.e., has normative fit). To test this hypothesis experimentally, D. van Knippenberg et al. gave participants bogus feedback on two alleged personality dimensions about the composition of a group to which they were assigned. One dimension was indicated as related to performance on the group task and the other dimension, to performance on a task the participants would perform individually later in the experiment. As predicted, group identification was only affected by group composition on the dimension indicated as relevant to group performance and not by the group composition on the other dimension. These results suggested that it is not difference per se but rather the belief that a difference is meaningful within the context of the group that leads diversity to affect categorization processes.

The final component underlying the salience of social categorization, cognitive accessibility of a categorization, refers to the ease with which the categorization comes to mind and the readiness of the perceiver to use the categorization. Accessibility depends on prior experience, beliefs, and expectations but also on contextual cues that may "prime" a categorization. Well-learned social categorizations that people have been socialized to use throughout their lives, such as those based on sex and age, should, for instance, be more accessible than nonobvious categorizations, such as those based on the color of people's cars or on toothpaste 
preference (Fiske, 1998; Stangor et al., 1992). Similarly, contextual cues such as a team supervisor who continually refers to functional differences may, for example, make a categorization based on functional background more accessible (Macrae, Bodenhausen, \& Milne, 1995; A. van Knippenberg \& Dijksterhuis, 2000).

Self-categorization theory proposes that the salience of a social categorization requires all three components just discussed and thus suggests that these components interact (Turner et al., 1987): The higher comparative fit, normative fit, and cognitive accessibility, the more likely a categorization is to be salient. Although it should be noted that to our knowledge, no study has yet tested the full three-way interaction, in support of this proposition, reviews of the social categorization literature have yielded consistent evidence for the two-way interactions implied in this three-way interaction (Oakes et al., 1994; A. van Knippenberg \& Dijksterhuis, 2000). In sum, then, we propose that differences among group members do not necessarily result in social categorization, nor do greater differences automatically result in stronger categorization. The extent to which they do so is contingent on perceivers' readiness to use the categorization, the extent to which the categorization is subjectively meaningful, and the extent to which the categorization results in relatively homogeneous categories that are clearly different from each other.

Proposition 5: Social categorization within work groups is contingent on the interaction of the comparative fit, the normative fit, and the cognitive accessibility of social categorizations.

Proposition 5 suggests that another reason why diversity research has yielded inconsistent results may be that the contingencies of social category salience typically have not been taken into account, and the clear implication for diversity research, therefore, is to develop research in this area, as we discuss below. There is, however, a second major consideration with regard to work-group diversity and social categorization processes, which is that social categorization should not be equated with intergroup biases.

\section{The Relationship Between Social Categorization and Intergroup Bias}

Even though research in intergroup relations identifies social categorization as the root cause of problematic intergroup attitudes and behavior, social categorization should not be equated with intergroup bias. Intergroup bias refers to more favorable perceptions of, and attitudes and behavior toward, in-group than outgroup (Brewer, 1979), whereas social categorization merely refers to the perceptual grouping of people (Turner et al., 1987). The distinction between social categorization and intergroup bias is important for diversity research, because the potentially negative effects of diversity identified in the social categorization perspective are clearly linked to intergroup bias and not to social categorization per se. Intergroup biases negatively influence affectiveevaluative reactions to diverse groups and their members. In effect, such biases may be expected to translate into the outcomes predicted in the social categorization perspective: low interpersonal liking and group cohesion, relational conflicts, low identification with and commitment to the group, low satisfaction, and high turnover (intentions), to name but a few (Williams \& O'Reilly,
1998). Diversity research has more or less ignored the distinction between categorization and bias and seems to proceed on the basis of the implicit assumption that bias is the inevitable consequence of categorization. Growing evidence suggests this assumption to be incorrect (Brewer \& Brown, 1998; Brown \& Gaertner, 2001; D. van Knippenberg, 2003), and thus points to the value of distinguishing between factors underlying categorization per se (i.e., Proposition 5) and factors underlying intergroup biases in diversity research.

Group memberships reflect on how individuals see the self (i.e., social identity). Accordingly, because individuals value a positive and distinctive self-image, group members value a positive and distinctive group identity (Brewer, 1991; Hogg \& Abrams, 1988; Tajfel \& Turner, 1986). As a result, intergroup biases are typically inspired by threats or challenges to the value or the distinctiveness of group identity (i.e., threats to individuals' self-views), whereas social categorization is less likely to result in intergroup biases in the absence of such threats or challenges (Branscombe, Ellemers, Spears, \& Doosje, 1999). Indeed, in the absence of such threats and challenges, diversity may sometimes be valued more than homogeneity (D. van Knippenberg \& Haslam, 2003). Threats to the value of identity may take many different forms but all share that a favorable image of the group is challenged. Such challenges may range from subtle social competition for status and prestige to outright derogation or discrimination of the group (e.g., Brewer \& Brown, 1998) and include unequal status of subgroups and competitive interdependence between subgroups (Gaertner \& Dovidio, 2000). Threats to distinctiveness may be experienced when the identity of the group as different from other groups is denied or suppressed, for instance, when management highlights a shared superordinate identity (e.g., organizational, work group) with an emphasis on within-group similarity that downplays differences between subgroups (Hornsey \& Hogg, 2000). This observation implies that trying to suppress categorizations may sometimes result in stronger intergroup biases than explicitly recognizing these categorizations in addition to recognizing the superordinate categorization as a work group (Hewstone \& Brown, 1986; Hornsey \& Hogg, 2000; van Leeuwen \& van Knippenberg, 2003; see also Gaertner \& Dovidio, 2000). As an illustration, consider Dovidio, Gaertner, and Validzic's (1998) study of intergroup bias in diverse groups. These authors found that intergroup biases were lower when subgroups had distinct roles (reducing distinctiveness threat) and equal status (reducing threats to value) and, at the same time, held more inclusive (superordinate) perceptual representations of the group.

Proposition 6: Social categorization results in intergroup biases that are disruptive to group functioning to the extent that the identity implied by the categorization is subjectively threatened or challenged.

\section{Research Implications of Propositions 5 and 6}

Proposition 5 points to the need to study the contingencies of social category salience in diversity research. Thus far, applications of the principles of the salience of social categorizations in diversity research are scarce and mainly concern comparative fit (e.g., Earley \& Mosakowski, 2000; Lau \& Murnighan, 1998). The principle of comparative fit suggests that different dimensions of diversity interact in eliciting social categorization processes. Part 
of the inconsistent findings in diversity research can thus be attributed to the independent effects approach (cf. Pelled et al., 1999), and diversity research would do well to shift to an interactive effects approach. Note, however, that testing interactions between dimensions of diversity by itself is insufficient, because a hypothesis about these interactive effects requires information about the extent to which the dimensions are correlated (i.e., to what extent do they converge or cross-cut each other?). This was nicely illustrated by Pelled et al., who obtained a number of interactions among dimensions of diversity. The authors found that the interactions had either positive or negative effects contingent on the correlation between the dimensions. The interactive effects of different dimensions of diversity may also be studied experimentally, bringing the correlation among dimensions under experimental control (e.g., Homan \& van Knippenberg, 2003; see below). Another option is the approach advanced by Thatcher, Jehn, and Zanutto (2003), who suggested replacing or complementing the similarity indices of diversity that are typically used in diversity research (i.e., reflecting similarity on a single dimension) by a measure that is based on similarities and differences on multiple dimensions simultaneously and that reflects the extent to which these differences converge or cross-cut each other.

The principle of normative fit suggests that in order to understand the relationship between diversity and social categorization, researchers should study not only group composition as such but also stereotypes and diversity beliefs, attitudes, and culture (Chatman, Polzer, Barsade, \& Neale, 1998; D. van Knippenberg \& Haslam, 2003). As the D. van Knippenberg et al. (2003) study suggested, however, these aspects should not necessarily be seen as general beliefs or attitudes about diversity but as more contextspecific. A diversity dimension that may be subjectively relevant in one context need not be so in another. This suggests that another reason for the inconsistent findings in diversity research is that a dimension of diversity may be subjectively meaningful in the context of one study but not in the context of another. A challenge to diversity research, therefore, is to develop theory to account for and predict the normative fit of dimensions of diversity. In the present context, an obvious starting point would be the effects that task requirements may have on normative fit (cf. D. van Knippenberg et al., 2003).

The role of cognitive accessibility, as of yet, has hardly been explored in diversity research. For some of the more frequently studied dimensions of diversity, such as gender, age, and ethnicity, accessibility might not be an issue, because such dimensions may be chronically accessible (Stangor et al., 1992; A. van Knippenberg \& Dijksterhuis, 2000). For other dimensions of diversity, however, such as functional differences, accessibility may be more of an issue, and it is worthwhile to explore how individual differences and contextual cues influence the accessibility of such categorizations in diverse work groups.

Proposition 6 suggests that because social categorization does not necessarily result in intergroup bias, diversity research should study intergroup bias in addition to social categorization. One of the things this implies is assessing rather than assuming social categorization and intergroup bias (for examples, see Gaertner \& Dovidio, 2000). Equally important is a focus on threats and challenges to identity as moderators of the relationship between social categorization and intergroup biases. This would involve assessing the role of such factors as subgroup status (Gaertner \& Dovidio, 2000; Hornsey \& Hogg, 2000), cooperative versus competitive intergroup relations (Gaertner \& Dovidio, 2000), and distinctive subgroup roles or functions (Hewstone \& Brown, 1986; van Leeuwen \& van Knippenberg, 2003).

Although recognizing differences may be important under some circumstances, individuals may also be categorized against their will (e.g., asking for the "female perspective" when this is seen as inappropriate; Moss Kanter, 1977). Such categorization threats (Branscombe et al., 1999) may invite individuals to distance themselves from the situation and the imposed categorization (Brewer, Manzi, \& Shaw, 1993; van Prooijen \& van Knippenberg, 2000). This poses a challenge from a more applied perspective, because it suggests that neither acknowledging nor downplaying categorizations has uniformly positive or negative effects. Diversity research thus should develop theory to predict the contingencies of distinctiveness threat and categorization threat in diverse work groups. Resolving this issue would greatly help diversity management in revealing under what circumstances diversity, and social categorizations, should be made an issue.

\section{Interactive Effects of Elaboration and Social Categorization Processes}

\section{Intergroup Bias May Disrupt Elaboration}

Propositions 1 through 4 concern elaboration as the core process underlying the positive effects of diversity, and Propositions 5 and 6 offer a more refined look at social categorization processes as potentially disruptive to diverse groups. As such, the propositions all point to potential reasons why research on diversity and performance has yielded such inconsistent results. In this section, we focus on yet another reason for the inconsistency in findings, which is the interaction between elaboration processes and social categorization processes in the relationship between work-group diversity and group performance.

As we noted in the introduction, the information/decisionmaking and social categorization perspectives have largely developed in separate traditions (Williams \& O'Reilly, 1998). Our analysis thus far has likewise considered these perspectives in isolation. Propositions 1 through 4 reflect a reconceptualization of information/decision-making processes, and Propositions 5 and 6 reflect a refinement of our thinking about the salience of social categorization and the not-so-inevitable link between social categorization and intergroup biases. In this section we integrate these two separate streams of thought and thus develop the CEM in full.

Research in persuasive communication has identified intergroup biases as a factor disrupting elaboration of others' communications. Intergroup biases lead people to place more trust in in-group than in out-group members and to see in-group members as more valid sources of information (Brewer, 1979; Turner et al., 1987) As a result, communications from in-group members are more likely to be attended to and elaborated, and thus more likely to influence the thoughts and actions of the individual, than are communications from out-group members (Mackie, Worth, \& Asuncion, 1990; D. van Knippenberg, 1999; D. van Knippenberg \& Wilke, 1992; see also Clark \& Maass, 1988). Because the elaboration of task-relevant information that is proposed to underlie the positive effects of work-group diversity on performance (Proposition 1) requires attention to and elaboration of communications from diverse others (i.e., as sources of novel information and perspectives), we propose that intergroup biases elicited by 
diversity interfere with diversity's potential to elicit elaboration of task-relevant information.

Consider, for example, a merger of two banks (cf. Buono, Bowditch, \& Lewis, 1985). Within newly formed teams providing financial services, a distinction between "us from our bank" and "them from the other bank" is easily made. This distinction, in and of itself, is not problematic. Intergroup biases, however, may lead team members to view the way of working that was customary at their former organization as superior to that of the other bank and to see team members from the other bank as less expert. These intergroup biases may also render team members less willing to invest in outgroup others and to keep them fully informed and up-to-date in matters concerning the team. As a result, elaboration of task-relevant information suffers, because team members exchange insufficient information and pay inadequate attention to perspectives and information introduced by outgroup others when preparing and developing financial services, and the synergy often hoped for in mergers is not achieved.

Proposition 7: Intergroup biases elicited by work-group diversity are disruptive to elaboration of task-relevant information and therefore to group performance.

Because diversity research typically has not focused on both information/decision-making and social categorization simultaneously, evidence from diversity research pertaining to our proposed integration of the two perspectives is rare. Bhappu, Griffith, and Northcraft (1997) compared mixed-gender groups with gender-homogeneous groups and found, in line with Proposition 7 , that diversity biased attention and influence in communication. Jehn et al. (1999) found that both social category diversity and value diversity were disruptive to positive relationships of informational diversity with performance indicators. It is unclear, however, whether the results of the Jehn et al. study should be attributed to the disruptive effects of intergroup biases elicited by social category and value diversity or to interactive effects with informational diversity on category salience (cf. comparative fit), or to both factors. Less ambiguous evidence in this respect comes from a recent experiment by Homan and van Knippenberg (2003) in which a manipulation of gender composition was crossed with a manipulation of informational diversity (using different sets of background information) to yield, amongst others, a condition in which informational diversity cross-cut gender diversity and a condition in which dimensions of diversity converged. Informational diversity was expected to elicit more elaboration (assessed in questionnaire data aggregated to the group level) but only if informational and gender diversity did not converge (cf. Proposition 5). Results supported this prediction and also showed that this pattern of results was complemented by higher interpersonal liking (as an indicator of lower intergroup bias) in the crosscategorization condition than in the other gender-diverse groups. These findings show that when diversity engenders categorization processes resulting in intergroup bias, elaboration of task-relevant information is disrupted.

\section{Research Implications of Proposition 7}

Thus, there is some evidence in support of Proposition 7 as well as evidence suggesting that the contingencies of social categorization identified in Proposition 5 moderate the extent to which diversity may give rise to intergroup biases that disrupt elaboration processes. Clearly, however, more research is needed, for instance, on the role of other contingencies of social categorization identified in Propositions 5 and the contingencies of intergroup bias identified in Proposition 6. In addition, an important implication of Proposition 7 is that when studying information/decision-making (i.e., elaboration) processes, one should assess social categorization and intergroup bias as well as elaboration and take the contingencies of social categorization and intergroup bias into consideration. Proposition 7 also suggests that one reason why diversity research has been rather unsuccessful in consistently linking diversity to performance is that the information/decisionmaking and social categorization perspectives have largely developed along separate lines, whereas categorization processes need to be taken into account to reliably predict elaboration processes.

\section{Categorization and Elaboration Are Not Tied to Specific Dimensions of Diversity}

\section{Social Category Diversity and Informational Diversity as Different Aspects of Diversity Dimensions}

Our analysis thus far has shown how a different and sometimes more refined look at the nature of information/decision-making processes and social categorization processes can help explain the inconsistent findings in diversity research. An issue we have not yet dealt with but that is also addressed by the CEM is whether some types of diversity are more or less likely to be associated with some of these processes (e.g., social categorization) than others. Past work tends to make a distinction between informational (functional, job-related) diversity and social category (demographic, not job-related) diversity. Information/decisionmaking processes have been linked to informational diversity, whereas social categorization processes have been associated with social category diversity (e.g., Jehn et al., 1999; Pelled et al., 1999). Qualitative (Milliken \& Martins, 1996; Williams \& O'Reilly, 1998) and quantitative (Bowers et al., 2000; Webber \& Donahue, 2001) reviews fail, however, to support this proposed association of diversity type with process and performance across studies. We have identified a number of reasons for the lack of empirical support. The CEM proposes yet another reason: the distinction between types of diversity is flawed.

The distinction between social category diversity and informational diversity may be intuitively appealing, but it is not as clear-cut as it may seem on first sight. It is not as easy as it might appear to determine which differences are task-relevant. Some dimensions of diversity are obviously task-relevant, such as differences in educational and functional background. Differences that appear not to be job-related at first sight, however, may also be associated with task-relevant information and perspectives. In developing personnel policy, for instance, married versus nonmarried individuals, men versus women, or older versus younger individuals may provide different task-relevant perspectives on what is important to employees, even though marital status, gender, and age are typically not seen as relevant criteria in selection for personnel management. In other words, what are typically seen as social category differences may be associated with task-relevant differences (Tsui \& O'Reilly, 1989). Social category differences thus are confounded with informational differences and, as a result, dimensions of diversity that are typically conceptualized as 
social category diversity (e.g., gender, ethnicity) may elicit the positive effects implied in the information/decision-making perspective (e.g., Cox et al., 1991), that is, as we argue in the present study, elaboration of task-relevant information and perspectives.

Conversely, informational differences may give rise to social categorization processes (e.g., Homan \& van Knippenberg, 2003; Marcus-Newhall et al., 1993). Not only may informational differences be visible through, for instance, differences in dress, nonvisible differences also may be recognized, form the basis for categorizations that seem meaningful, and be readily used within a particular context (e.g., the economists vs. the psychologists in a business school, opponents vs. proponents of a particular position). Thus, what may appear to be clear informational differences may in practice work as social category differences, acting as a basis for categorization processes in their own right. We therefore propose that informational diversity and social category diversity are aspects or functions of diversity rather than types of diversity, the key point being that all dimensions of diversity may elicit categorization processes as well as elaboration processes.

Proposition 8: All dimensions of diversity may elicit social categorization processes as well as elaboration processes.

\section{Research Implications of Proposition 8}

An important implication of Proposition 8 is that if any dimension of diversity can function as both social category diversity and informational diversity, any dimension can elicit both the effects associated with elaboration processes and the effects associated with categorization processes. Any model of diversity, then, that assumes that categorization processes are tied to certain dimensions of diversity while elaboration (cf. information/decision making) processes are tied to other dimensions is bound to fall short of reliably predicting the positive and negative performance effects of diversity. The clear implication for diversity research therefore is to abandon the focus on typologies of diversity to explain the differential effects of diversity, and to focus on the contingencies of elaboration, categorization, and intergroup bias to predict which function of diversity will prevail in a given context.

Research on group tenure and diversity suggests that the function of dimensions of diversity may change over time. A number of studies show that diverse groups may initially perform worse than more homogeneous groups but, over time, may perform as well as or even outperform homogeneous groups (Earley \& Mosakowski, 2000; Schippers, Den Hartog, Koopman, \& Wienk, 2003; Watson, Kumar, \& Michaelsen, 1993; see also Gruenfeld, Mannix, Williams, \& Neale, 1996). In addition, Harrison, Price, and Bell (1998) found a negative relationship between demographic diversity and team integration (a concept akin to cohesion) that diminished over time, whereas a negative relationship of attitude diversity with integration only became apparent over time. These moderating roles of tenure may be explained from Proposition 8 and the contingencies of elaboration, categorization, and intergroup bias.

First, group members may need time to develop the knowledge, skills, and abilities required to elaborate divergent perspectives and to develop a shared sense of "who knows what," that is, shared knowledge, referred to as transactive memory (Wegner, 1986), or a shared mental model of the group (Cannon-Bowers \& Salas, 2001). Transactive memory affects the team's ability for elabora- tion, because it helps determine which group members to consult on particular issues and provides a frame of reference for placing the individual's contribution in context (Moreland, 1999). Second, comparative fit may change as new similarities and differences are uncovered through interaction (cf. Swann, Polzer, Seyle, \& Ko, 2004). Similarly, normative fit may change as people get to know dissimilar others better over time and as experience overrides stereotype-based perceptions of similarities and differences (Gaertner \& Dovidio, 2000; Harrison et al., 1998). Extended tenure may thus result in lower salience of the categorizations initially engendered by diversity. In combination, this suggests a shift over time from categorization processes to information/ decision-making processes, which explains the change in performance of diverse groups relative to homogeneous groups observed in diversity research. At the same time, however, as Harrison et al.'s (1998) findings for attitude diversity suggest, over time groups may also uncover more hidden differences that may give rise to disruptive categorization processes. The conclusion should therefore be that the processes elicited by diversity may change over time rather than that there will always be a shift from categorization to elaboration processes. The earlier studies of the moderating role of group tenure were not designed to test the proposed roles of elaboration, categorization, and intergroup bias, however, and more process-oriented research on the moderating role of tenure is clearly needed to substantiate this conclusion.

There seems to be an emerging interest in other dimensions of diversity, such as diversity in personality (e.g., Barrick, Stewart, Neubert, \& Mount, 1998; Van Vianen \& De Dreu, 2001), attitudes (e.g., Harrison et al., 1998), and values (e.g., Jehn et al., 1999). An obvious question from the perspective of the current discussion is to what extent Proposition 8 also applies to these dimensions. It seems obvious that differences in attitudes and values may introduce different perspectives as well as different information associated with these perspectives. Personality differences too may be associated with divergent perspectives and information, because an individual's personality is likely to shape the individual's background, invite specific experiences, and so forth. At the same time, differences on all of these dimensions may lead to the perception that others are different from the self and invite social categorization processes. Indeed, Harrison, Price, Gavin, and Florey (2002; also see Harrison et al., 1998) found that diversity in personality, beliefs, attitudes, and values was negatively related to team integration. Thus, it appears plausible that diversity in attitudes, values, and personality may elicit both elaboration and social categorization processes. Assessing these processes, and the contingencies of these processes, would be a worthwhile avenue for future research in this area.

\section{Implications for Diversity Management}

Although the primary aim of our analysis is to address the inconsistent research findings for diversity and performance, and to outline the implications of our model for diversity research, the CEM has a number of implications for the management of diversity. In short, the model suggests that to harvest the potential benefits of work-group diversity, and to prevent its potentially disruptive effects, diversity management should focus on fostering elaboration (Proposition 1) and on preventing intergroup biases that are associated with negative affective-evaluative reactions to the group and its members (Proposition 6) and that may disrupt 
elaboration of task-relevant information (Proposition 7). The moderators of elaboration (Proposition 2, 3, and 4), categorization (Proposition 5), and intergroup bias (Proposition 6) we identified provide guidelines for management in these respects.

Proposition 2, for instance, implies that team composition decisions may favor a diverse composition to the extent that task requirements are conducive to the positive effects of diversity. The proposition also suggests that diversity management should work from the realization that task requirements impose important constraints on the extent to which positive effects of diversity on group performance may be expected. For tasks that have strong information-processing and decision-making components, the CEM implies that diversity management should focus on task motivation (Proposition 3) and task ability (Proposition 4). Motivation, for instance, may be fostered by leadership that builds intrinsic motivation (e.g., D. van Knippenberg \& Hogg, 2003), by treating group members fairly and respectfully (Tyler, 1999), by providing organizational and supervisor support (Rhoades \& Eisenberger, 2002), and by setting challenging goals (Locke \& Latham, 1990). Ability may in part be managed through selection, that is, by selecting individuals high in cognitive ability, taskspecific knowledge, skills, and abilities, and communication skills into the work group. When it comes to selection and work-group composition, our analysis of the moderating role of ability also suggests that groups can become too diverse. To the extent that this occurs at management's discretion, then, differences should be sought in moderation. Group members' ability to elaborate diverse information may also develop over time as members become more familiar with each others' perspectives and develop transactive memory. This suggests that especially for diverse work groups it is important that they can reach more extended tenure and that they be allowed a more extended start-up phase than more homogeneous groups. Alternatively, training or leadership to recognize differences in expertise and perspective may to a certain extent substitute for extended tenure (Moreland, 1999; also see Stasser, Vaughan, \& Stewart, 2000).

Propositions 5 and 6 suggest that preventing disruptive intergroup biases begins with the process of managing the salience of social categories. Because it is unrealistic to assume that diversity management successfully lowers the salience of all social categorizations in each and every work group, diversity management should also focus on managing the contingencies of intergroup biases. Notions of social category salience suggest, for instance, that comparative fit more than difference per se contributes to social categorization salience. Eliminating diversity may be neither feasible nor desirable, but preventing high comparative fit in work-group composition should be a more realistic ambition, because it does not require lowering diversity (cf. crosscategorization). Team and work-group composition could thus focus on cross-cutting dimensions of diversity, both for desired (e.g., functional) and "natural" (e.g., demographic) dimensions of diversity. Work by D. van Knippenberg et al. (2003; D. van Knippenberg \& Haslam, 2003) suggests that even when categorizations have normative fit and are salient, negative responses to diversity need not result. These studies show that when differences are seen as valuable to group functioning, group members may respond more positively to diverse groups than to more homogeneous groups. Thus, part of the process of managing diversity could also involve fostering such value-in-diversity beliefs and attitudes (Ely \& Thomas, 2001; D. van Knippenberg \& Haslam,
2003). A focus on the value of diversity for the work group may also build mutual respect and address potential threats to the value and distinctiveness of identities (cf. Proposition 6).

Proposition 8 implies that the above-mentioned guidelines essentially hold for all dimensions of diversity. Diversity management therefore should not rely on typologies of diversity that imply that only certain dimensions of diversity may yield positive effects, whereas other dimensions of diversity may at best not be disruptive, but instead work from the assumption that all dimensions of diversity can stimulate performance through information elaboration as well as hinder performance by causing disruptive intergroup biases.

\section{Conclusion: Setting the Research Agenda}

The starting point for the current analysis was the inconsistency in the various findings for the relationship between work-group diversity and performance. To address this problem, we advanced the CEM of work-group diversity and group performance. The CEM centers around eight propositions, each in its own right reflecting a different or more refined look at the way work-group diversity affects - through information/decision-making (i.e., elaboration) processes and social categorization processes-workgroup performance. In addition to integrating past work on diversity in such a way that many inconsistencies in research findings can be explained, the CEM points to the need to study the processes underlying the effects of work-group diversity. Because all dimensions of diversity can, in principle, have both positive and negative effects, processes cannot be assumed on the basis of the dimension of diversity studied. Nor can they be assumed on the basis of the relationship between diversity and performance: Social categorization itself is not problematic, and elaboration processes also can lead to negative effects (i.e., when group ability is not up to par with group diversity). Thus, we echo recent calls for process-oriented research on work-group diversity (Lawrence, 1997; Pelled et al., 1999), because such a focus will greatly improve our understanding of the effects diversity can have.

Although our core propositions are consistent with laboratory and field research on work-group diversity, many aspects of the CEM require new research. For example, the CEM points to moderating and mediating variables that have been ignored thus far. Testing moderating relationships requires an increased focus on statistical interaction effects instead of main effects. Because statistical interactions are typically underestimated in survey research (McClelland \& Judd, 1993), proper assessment of the proposed interactions requires complementing cross-sectional research with controlled experiments. In the previous sections, we have discussed several examples of what such experiments could look like.

Our analysis focused on group performance more than on other possible effects of diversity, such as turnover or commitment. One reason is that the divergent perspectives on the positive versus the negative effects of diversity primarily concern diversity's effects on group performance (i.e., the need for integration is greatest here). A second reason is that diversity effects on other frequently studied outcomes such as cohesion, commitment, and turnover may be assumed to reflect in part the same processes that lead to diversity's effects on group performance and are indeed included in the CEM (cf. Proposition 6). Ultimately, however, it should be recognized that our discussion and our model do not concern all 
possible effects of diversity. We excluded discussion of such issues as the relationship of diversity with the group's ability to maintain external relationships (Ancona \& Caldwell, 1992), because these issues relate to a different set of processes than the group dynamics involved in the more proximal effects of diversity, and incorporation of these processes would go beyond the scope of the present study. Exploring the implications of the CEM for other outcomes than performance seems, however, an important avenue for future research and theory development.

In conclusion, the present study provides a renewed and refined look at the information-processing and social categorization processes triggered by work-group diversity. In providing this perspective, we have integrated theoretical accounts of work-group diversity, explained inconsistencies in past research findings, and suggested several avenues for future research. We hope that the combination of such research efforts will yield realistic advice concerning how to manage effective performance in work groups in an increasingly diverse society.

\section{References}

Ancona, D. G., \& Caldwell, D. F. (1992). Demography and design: Predictors of new product team performance. Organization Science, 3 , 321-341.

Bantel, K., \& Jackson, S. (1989). Top management and innovations in banking: Does the composition of the team make a difference? Strategic Management Journal, 10, 107-124.

Barrick, M. R., Stewart, G. L., Neubert, M. J., \& Mount, M. K. (1998). Relating member ability and personality of work-team processes and team effectiveness. Journal of Applied Psychology, 83, 377-391.

Bhappu, A. D., Griffith, T. L., \& Northcraft, G. B. (1997). Media effects and communication bias in diverse groups. Organizational Behavior and Human Decision Processes, 70, 199-205.

Bowers, C., Pharmer, J. A., \& Salas, E. (2000). When member homogeneity is needed in work teams: A meta-analysis. Small Group Research, 31, 305-327.

Branscombe, N. R., Ellemers, N., Spears, R. \& Doosje, B. (1999). The context and content of social identity threat. In N. Ellemers, R. Spears, \& B. Doosje (Eds.), Social identity: Context, commitment, content (pp. 35-58). Oxford, UK: Blackwell Science.

Brewer, M. B. (1979). In-group bias in the minimal intergroup situation: A cognitive-motivational analysis. Psychological Bulletin, 86, 307-324.

Brewer, M. B. (1991). The social self: On being the same and different at the same time. Personality and Social Psychology Bulletin, 17, 475482.

Brewer, M. B. (1995). Managing diversity: The role of social identities. In S. E. Jackson \& M. N. Ruderman (Eds.), Diversity in work teams (pp. 47-68). Washington, DC: American Psychological Association.

Brewer, M. B., \& Brown, R. J. (1998). Intergroup relations. In D. T. Gilbert \& S. T. Fiske (Eds.), Handbook of social psychology, (4th ed., pp. 554-594). Boston: McGraw-Hill.

Brewer, M. B, Manzi, J. M., \& Shaw, J. S. (1993). In-group identification as a function of depersonalization, distinctiveness, and status. Psychological Science, 4, 88-92.

Brodbeck, F. (2003, May). Contradiction as an inhibitor and facilitator of group performance. Paper presented at the 11th European Congress of Work and Organizational Psychology, Lisbon, Portugal.

Brown, R., \& Gaertner, S. L. (2001). Intergroup processes. Malden, MA: Blackwell.

Buono, A. F., Bowditch, J. L., \& Lewis, J. W. (1985). When cultures collide: The anatomy of a merger. Human Relations, 38, 477-500.

Cannon-Bowers, J. A., \& Salas, E. (2001). Reflections on shared cognition. Journal of Organizational Behavior, 22, 195-202.
Chaiken, S., \& Trope, Y. (1999). Dual process theories in social psychology. New York: Guilford Press.

Chatman, J. A., Polzer, J. T., Barsade, S. G., \& Neale, M. A. (1998). Being different yet feeling similar: The influence of demographic composition and organizational culture on work group processes and outcomes. Administrative Science Quarterly, 43, 749-780.

Clark, R. D., \& Maass, A. (1988). Social categorization in minority influence: The case of homosexuality. European Journal of Social Psychology, 18, 347-364.

Cox, T. H., Lobel, S. A., \& McLeod, P. L. (1991). Effects of ethnic group cultural differences on cooperative and competitive behavior on a group task. Academy of Management Journal, 34, 827-847.

De Dreu, C. K. W., \& Carnevale, P. J. (2003). Motivational bases of information processing and strategy in conflict negotiation. Advances in Experimental Social Psychology, 35, 235-291.

De Dreu, C. K. W., Harinck, S., \& van Vianen, A. E. M. (1999). Conflict and performance in groups and organizations. In C. L. Cooper \& I. T. Robertson (Eds.), International review of industrial and organizational psychology (Vol. 14, pp. 369-414). Chichester, United Kingdom: Wiley.

De Dreu, C. K. W., \& Weingart, L. R. (2003a). A contingency theory of task conflict and performance in groups and organizational teams. In M. West, D. Tjosvold, \& K. G. Smith (Eds.), International handbook of organizational teamwork and cooperative working (pp. 151-166). Chichester, United Kingdom: Wiley.

De Dreu, C. K. W., \& Weingart, L. R. (2003b). Task and relationship conflict, team performance, and team member satisfaction: A metaanalysis. Journal of Applied Psychology, 88, 741-749.

De Dreu, C. K. W., \& West, M. A. (2001). Minority dissent and team innovation: The importance of participation in decision making. Journal of Applied Psychology, 86, 1191-1201.

Dovidio, J. F., Gaertner, S. L., \& Validzic, A. (1998). Intergroup bias: Status, differentiation, and a common in-group identity. Journal of Personality and Social Psychology, 75, 109-120.

Eagly, A. H., \& Chaiken, S. (1993). The psychology of attitudes. Orlando, FL: Harcourt Brace Jovanovich.

Earley, P. C., \& Mosakowski, E. (2000). Creating hybrid team cultures: An empirical test of transnational team functioning. Academy of Management Journal, 43, 26-49.

Ely, R. J., \& Thomas, D. A. (2001). Cultural diversity at work: The effects of diversity perspectives on work group processes and outcomes. Administrative Science Quarterly, 46, 229-273.

Fiske, S. T. (1998). Stereotyping, prejudice, and discrimination. In D. T. Gilbert, S. T. Fiske, \& G. Lindzey (Eds.), Handbook of social psychology (4th ed., pp. 357-411). Boston: McGraw-Hill.

Gaertner, S. L., \& Dovidio, J. F. (2000). Reducing intergroup bias. The common ingroup identity model. Philadelphia: Psychology Press.

Gonzalez-Roma, V., West, M. A., \& Borrill, C. S. (2003). Demographic diversity and team innovation: Testing a curvilinear relationship model. Unpublished manuscript, University of Valencia.

Gruenfeld, D. H., Mannix, E. A., Williams, K. Y., \& Neale, M. A. (1996). Group composition and decision making: How member familiarity and information distribution affect process and performance. Organizational Behavior and Human Decision Processes, 67, 1-15.

Guzzo, R., \& Dickson, M. (1996). Teams in organizations: Recent research on performance and effectiveness. Annual Review of Psychology, 47, 307-338.

Harrison, D. A., Price, K. H., \& Bell, M. P. (1998). Beyond relational demography: Time and the effects of surface- and deep-level diversity on work group cohesion. Academy of Management Journal, 41, 96-107.

Harrison, D. A., Price, K. H., Gavin, J. H., \& Florey, A. T. (2002). Time, teams, and task performance: Changing effects of surface- and deeplevel diversity on group functioning. Academy of Management Journal, 45, 1029-1045.

Hewstone, M., \& Brown, R. (1986). Contact is not enough: An intergroup 
perspective on the 'contact hypothesis.' In M. Hewstone \& R. Brown (Eds.), Contact and conflict in intergroup encounters, (pp. 1-44). Cambridge, MA: Blackwell.

Hinsz, V. B., Tindale, R. S., \& Vollrath, D. A. (1997). The emerging conceptualization of groups as information processes. Psychological Bulletin, 121, 43-64.

Hogg, M. A., \& Abrams, D. (1988). Social identifications: A social psychology of intergroup relations and group processes. London, United Kingdom: Routledge.

Homan, A. C., \& van Knippenberg, D. (2003, May). The beneficial effects of cross-categorizing informational and demographical diversity in groups. Paper presented at the 11th European Congress of Work and Organizational Psychology, Lisbon, Portugal.

Hornsey, M. J., \& Hogg, M. A. (2000). Assimilation and diversity: An integrative model of subgroup relations. Personality and Social Psychology Review, 4, 143-156.

Hunter, J. E., \& Schmidt, F. L. (1996). Intelligence and job performance: Economic and social implications. Psychology, Public Policy, and Law, 2, 447-472.

Jackson, S. E. (1992). Team composition in organizational settings: Issues in managing an increasingly diverse workforce. In S. Worchel, W. Wood, \& J. A. Simpson (Eds.), Group processes and productivity (pp. 136-180). Newbury Park, CA: Sage.

Jehn, K. (1995). A multimethod examination of the benefits and detriments of intragroup conflict. Administrative Science Quarterly, 40, 256-282.

Jehn, K. A., Northcraft, G. B., \& Neale, M. A. (1999). Why differences make a difference: A field study of diversity, conflict, and performance in workgroups. Administrative Science Quarterly, 44, 741-763.

Kozlowski, S. W. J., \& Bell, B. S. (2003). Work groups and teams in organizations. In W. C. Borman \& D. R. Ilgen (Eds.), Handbook of psychology: Industrial and organizational psychology (Vol. 12, pp. 333-375). New York: Wiley.

Kruglanski, A. W., \& Webster, D. M. (1991). Group members' reactions to opinion deviates and conformists at varying degrees of proximity to decision deadline and of environmental noise. Journal of Personality and Social Psychology, 61, 212-225.

Kruglanski, A. W., \& Webster, D. M. (1996). Motivated closing of the mind: "Seizing" and "freezing." Psychological Review, 103, 263-283.

Lau, D. C., \& Murnighan, J. K. (1998). Demographic diversity and faultlines: The compositional dynamics of organizational groups. Academy of Management Review, 23, 325-340.

Lawrence, B. S. (1997). The black box of organizational demography. Organization Science, 8, 1-22.

Lerner, J. S., \& Tetlock, P. E. (1999). Accounting for the effects of accountability. Psychological Bulletin, 125, 255-275.

Locke, E. A., \& Latham, G. P. (1990). A theory of goal setting and task performance. Upper Saddle River, NJ: Prentice-Hall.

Lovelace, K., Shapiro, D. L., \& Weingart, L. R. (2001). Maximizing cross-functional new product teams' innovativeness and constraint adherence: A conflict communications perspective. Academy of Management Journal, 44, 779-793.

Mackie, D. M., Worth, L. T., \& Asuncion, A. G. (1990). Processing of persuasive in-group messages. Journal of Personality and Social Psychology, 58, 812-822.

Macrae, C. N., Bodenhausen, G. V., \& Milne, A. B. (1995). The dissection of selection in person perception: Inhibitory processes in social stereotyping. Journal of Personality and Social Psychology, 69, 397-407.

Marcus-Newhall, A., Miller, N., Holtz, R., \& Brewer, M. B. (1993). Cross-cutting category membership with role assignment: A means of reducing intergroup bias. British Journal of Social Psychology, 32, 125-146.

McClelland, G. H., \& Judd, C. M. (1993). Statistical difficulties of detecting interactions and moderator effects. Psychological Bulletin, 114, 376-390.
McGrath, J. E. (1984). Groups: Interaction and performance. Englewood Cliffs, NJ: Prentice-Hall.

Milliken, F., \& Martins, L. (1996). Searching for common threads: Understanding the multiple effects of diversity in organizational groups. Academy of Management Review, 21, 402-433.

Moreland, R. L. (1999). Transactive memory: Learning who knows what in work groups and organizations. In L. L. Thompson, J. M. Levine, \& D. M. Messick (Eds.), Shared cognition in organizations (pp. 3-31). Mahwah, NJ: Erlbaum.

Moss Kanter, R. (1977). Men and women of the corporation. New York: Basic Books.

Mullen, B., \& Copper, C. (1994). The relation between group cohesiveness and performance: An integration. Psychological Bulletin, 115, 210-227.

Murnighan, J. K., \& Conlon, D. E. (1991). The dynamics of intense work groups: A study of British string quartets. Administrative Science Quarterly, 36, 165-186.

Oakes, P. J., Haslam, S. A., \& Turner, J. C. (1994). Stereotyping and social reality. Malden, MA: Blackwell.

Oakes, P. J., Turner, J. C., \& Haslam, S. A. (1991). Perceiving people as group members: The role of fit in the salience of social categorizations. British Journal of Social Psychology, 30, 125-144.

O'Reilly, C. A., Caldwell, D. F., \& Barnett, W. P. (1989). Work group demography, social integration, and turnover. Administrative Science Quarterly, 34, 21-37.

Pelled, L. H., Eisenhardt, K. M., \& Xin, K. R. (1999). Exploring the black box: An analysis of work group diversity, conflict, and performance. Administrative Science Quarterly, 44, 1-28.

Randel, A. E. (2002). Identity salience: A moderator of the relationship between group gender composition and work group conflict. Journal of Organizational Behavior, 23, 749-766.

Rhoades, L., \& Eisenberger, R. (2002). Perceived organizational support: A review of the literature. Journal of Applied Psychology, 87, 698-714.

Riordan, C., \& Shore, L. (1997). Demographic diversity and employee attitudes: Examination of relational demography within work units. Journal of Applied Psychology, 82, 342-358.

Schippers, M. C., Den Hartog, D. N., Koopman, P. L., \& Wienk, J. A. (2003). Reflexivity and diversity in teams: The moderating effects of outcome interdependence and group longevity. Journal of Organizational Behavior, 24, 729-802.

Scholten, L., van Knippenberg, D., Nijstad, B. A., \& De Dreu, C. K. W (2003). Epistemic motivation and group decision making. Unpublished manuscript, University of Amsterdam.

Schweiger, D. M., Sandberg, W. R., \& Rechner, P. L. (1989). Experiential effects of dialectical inquiry, devil's advocacy, and consensus approaches to strategic decision making. Academy of Management Journal, 32, 745-772.

Schwenk, C. R. (1990). Effects of devil's advocacy and dialectical inquiry on decision making: A meta-analysis. Organizational Behavior and Human Decision Processes, 47, 161-176.

Simons, T., Pelled, L. H., \& Smith, K. A. (1999). Making use of difference: Diversity, debate, and decision comprehensiveness in top management teams. Academy of Management Journal, 42, 662-674.

Simons, T., \& Peterson, R. (2000). Task conflict and relationship conflict in top management teams: The pivotal role of intragroup trust. Journal of Applied Psychology, 85, 102-111.

Stangor, C., Lynch, L., Duan, C., \& Glass, B. (1992). Categorization of individuals on the basis of multiple social features. Journal of Personality and Social Psychology, 62, 207-218.

Stasser, G. (1999). The uncertain role of unshared information in collective choice. In L. L. Thompson, J. M. Levine, \& D. M. Messick (Eds.), Shared cognition in organizations, (pp. 49-69). Mahwah, NJ: Erlbaum.

Stasser, G., Vaughan, S. I., \& Stewart, D. D. (2000). Pooling unshared information: The benefits of knowing how access to information is distributed among group members. Organizational Behavior and $\mathrm{Hu}$ man Decision Processes, 82, 102-116. 
Stewart, G. L., \& Barrick, M. R. (2000). Team structure and performance: Assessing the mediating role of intrateam process and the moderating role of task type. Academy of Management Journal, 43, 135-148.

Swann, W. B., Polzer, J. T., Seyle, D. C., \& Ko, S. J. (2004). Finding value in diversity: Verification of personal and social self-views in diverse groups. Academy of Management Review, 29, 9-27.

Tajfel, H., \& Turner, J. (1986). The social identity of intergroup behavior. In W. A. S. Worchel (Ed.), Psychology and intergroup relations. Chicago: Nelson-Hall.

Thatcher, S. M. B., Jehn, K. A., \& Zanutto, E. (2003). Cracks in diversity research: The effects of diversity faultlines on conflict and performance. Group Decision and Negotiation, 12, 217-241.

Tjosvold, D. (1998). Cooperative and competitive goal approach to conflict: Accomplishments and challenges. Applied Psychology: An International Review, 47, 285-342.

Triandis, H. C., Kurowski, L. L., \& Gelfand, M. J. (1994). Workplace diversity. In H. C. Triandis, M. P. Dunnette, \& L. M. Hough (Eds.), Handbook of industrial and organizational psychology (2nd ed., Vol. 4, pp. 769-827). Palo Alto, CA: Consulting Psychologists Press.

Tsui, A. S., Egan, T. D., \& O'Reilly, C. A. (1992). Being different: Relational demography and organizational attachment. Administrative Science Quarterly, 37, 549-579.

Tsui, A. S., \& O'Reilly, C. A. (1989). Beyond simple demographic effects: The importance of relational demography in superior-subordinate dyads. Academy of Management Journal, 32, 402-423.

Turner, J. C., Hogg, M. A., Oakes, P. J., Reicher, S. D., \& Wetherell, M. S. (1987). Rediscovering the social group: A self-categorization theory. Oxford, United Kingdom: Blackwell.

Tyler, T. R. (1999). Why people cooperate with organizations: An identitybased perspective. Research in Organizational Behavior, 21, 201-246.

Van de Ven, A. H., Delbecq, A., \& Koenig, R. H. (1976). Determinants of coordination modes within organizations. American Sociological Review, 41, 322-338.

van Ginkel, W., \& van Knippenberg, D. (2003, September). The role of shared mental models for informational diversity in group decision making. Paper presented at the European Association of Experimental Social Psychology Small Group Meeting on Small Group Decision Making, Amsterdam.

van Knippenberg, A., \& Dijksterhuis, A. (2000). Social categorization and stereotyping: A functional perspective. European Review of Social Psychology, 11, 105-144.

van Knippenberg, D. (1999). Social identity and persuasion: Reconsidering the role of group membership. In D. Abrams \& M. A. Hogg (Eds.), Social identity and social cognition, (pp. 315-331). Oxford, United Kingdom: Blackwell.

van Knippenberg, D. (2003). Intergroup relations in organizations. In M. West, D. Tjosvold, \& K. G. Smith (Eds.), International handbook of organizational teamwork and cooperative working (pp. 381-399). Chichester, United Kingdom: Wiley.

van Knippenberg, D., \& Haslam, S. A. (2003). Realizing the diversity dividend: Exploring the subtle interplay between identity, ideology, and reality. In S. A. Haslam, D. van Knippenberg, M. J. Platow, \& N. Ellemers (Eds.), Social identity at work: Developing theory for organizational practice (pp. 61-77). New York: Psychology Press.

van Knippenberg, D., Haslam, S. A., \& Platow, M. J. (2003, May). Work group diversity and work group identification: Diversity as an aspect of group identity. Paper presented at the 11th European Congress of Work and Organizational Psychology, Lisbon, Portugal.

van Knippenberg, D., \& Hogg, M. A. (2003). A social identity model of leadership effectiveness in organizations. Research in Organizational Behavior, 25, 243-295.

van Knippenberg, D., \& Wilke, H. (1992). Prototypicality of arguments and conformity to in-group norms. European Journal of Social Psychology, 22, 141-155.

van Leeuwen, E., \& van Knippenberg, D. (2003). Organizational identification following a merger: The importance of agreeing to differ. In S. A. Haslam, D. van Knippenberg, M. J. Platow, \& N. Ellemers (Eds.), Social identity at work: Developing theory for organizational practice (pp. 205-221). New York: Psychology Press.

van Prooijen, J. W., \& van Knippenberg, D. (2000). Individuation or depersonalization: The influence of personal status position. Group Processes and Intergroup Relations, 3, 63-77.

Van Vianen, A. E. M., \& De Dreu. C. K. W. (2001). Personality in teams: Its relationship to social cohesion, task cohesion, and team performance. European Journal of Work and Organizational Psychology, 10, 97-120.

Wagner, W., Pfeffer, J., \& O'Reilly, C. (1984). Organizational demography and turnover in top management groups. Administrative Science Quarterly, 29, 74-92.

Watson, W., Kumar, K., \& Michaelsen, L. (1993). Cultural diversity's impact on interaction processes and performance: Comparing homogeneous and diverse task groups. Academy of Management Journal, 36, $590-602$.

Weaver, J. L., Bowers, C. A., Salas, E., \& Cannon-Bowers, J. A. (1997) Motivation in teams. In M. M. Beyerlein \& D. A. Johnson (Eds.), Advances in interdisciplinary studies of work teams (Vol. 4, pp. 167191). Stamford, CT: JAI Press.

Webber, S. S., \& Donahue, L. M. (2001). Impact of highly and less job-related diversity on work group cohesion and performance: A metaanalysis. Journal of Management, 27, 141-162.

Wegner, D. M. (1986). Transactive memory: A contemporary analysis of the group mind. In B. Mullen \& G. R. Goethals (Eds.), Theories of group behavior (pp. 185-208). New York: Springer-Verlag.

Williams, K. Y., \& O'Reilly, C. A. (1998). Demography and diversity in organizations: A review of 40 years of research. Research in Organizational Behavior, 20, 77-140

Wood, W. (1987). Meta-analytic review of sex differences in group performance. Psychological Bulletin, 102, 53-71.

Received June 26, 2003

Revision received June 14, 2004

Accepted June 29, 2004 